\title{
Cytokine expression and the role of Th17 cells in a mouse model of colitis
}

\author{
YING HE, LIAN-JIE LIN, CHANG-QING ZHENG, YU JIN and YAN LIN \\ Shengjing Hospital of China Medical University, Shenyang, Liaoning 110004, P.R. China
}

Received May 13,2012; Accepted September 10, 2012

DOI: $10.3892 / \mathrm{mmr} .2012 .1111$

\begin{abstract}
The aim of this study was to explore the expression of cytokines by Th17 cells and their mechanisms of action in a mouse model of 2,4,6-trinitrobenzenesulfonic acid (TNBS)-induced inflammatory bowel disease (IBD). ELISA was used to detect the expression of the Th17 cytokine interleukin, (IL)-17, and that of the Th1 cytokine, interferon- $\gamma$ (IFN- $\gamma$ ), in colon tissues. Western blot analysis was used to detect IL-17 expression in the peripheral blood mononuclear cells (PBMCs), spleen mononuclear cells (SMCs), mesenteric lymph node cells and colon tissues of the colitic mice. RT-PCR analysis was used to detect the effect of anti-IL-17 antibody application on the tumor necrosis factor (TNF)- $\alpha$, IFN- $\gamma$ and IL-6 mRNA levels in the SMCs of the colitic mice. The Th17 cytokine, IL-17, and the Th1 cytokine, IFN- $\gamma$, were expressed at high levels in the TNBS-induced colitic mice. In addition, the expression of the Th17 cytokine appeared earlier than that of the Th1 cytokine. The IL-17 levels in the SMCs, mesenteric lymph node cells and colon tissues of the disease model group were significantly different from those of the normal control group $(\mathrm{p}<0.01)$, while the IL-17 levels in the PBMCs of the disease model group were not significantly different $(p>0.05)$ from those of the control group. Following the application of $10 \mu \mathrm{g} / \mathrm{ml}$ anti-IL-7 antibody, the TNF- $\alpha$, IL- 6 and IFN- $\gamma$ mRNA levels in the SMCs of the model group demonstrated no significant differences from those of the non-antibody-treated control group ( $\mathrm{p}>0.05)$. In conclusion, Th17 and Th1 cells are involved in TNBS-induced IBD and the effect of the Th17 cells may be mediated through the induction of the secretion of pro-inflammatory cytokines.
\end{abstract}

\section{Introduction}

Inflammatory bowel disease (IBD) is a type of chronic gastrointestinal tract-specific inflammation with unclear etiology, that

Correspondence to: Professor Chang-Qing Zheng, Shengjing Hospital of China Medical University, 36 Sanhao Street, Heping, Shenyang, Liaoning 110004, P.R. China

E-mail: changqingzheng@126.com

Key words: Th17 cells, Th1 cells, inflammatory bowel disease, interleukin-17, interferon- $\gamma$, tumor necrosis factor- $\alpha$, interleukin- 6 belongs to the category of autoimmune disease. The incidence of IBD is increasing and it has become a common digestive system disease and a major cause of chronic diarrhea (1). The disease is now considered to be primarily mediated by an immune response, as well as involving genetic and environmental factors. Dysfunction of immune regulation may be the key factor in its pathogenesis (2,3). Th1 cells are considered to be closely related to IBD pathogenesis; however, the nature of this relationship has not been fully explained. A new $\mathrm{CD}^{+}$ helper T cell subtype, Th17, has been identified, which is named after the major cytokine it secretes, interleukin (IL)-17. Previous studies have suggested that Th17 cells are important in the pathogenesis of autoimmune diseases, and these cells have therefore become a popular topic for immunological studies (4,5). In the current study, 2,4,6-trinitrobenzenesulfonic acid (TNBS) was used to establish an animal model of IBD, and the mutual relationship of Th17 and Th1 cells in the pathogenesis of IBD was explored using this model. In addition, a monoclonal antibody against the Thl7 cytokine was used to specifically block IL-17 in order to observe its effect on other pro-inflammatory cytokines. The exploration of the expression of cytokines by Th17 cells in IBD mice and investigation of the mechanisms should provide new therapeutic directions for the treatment of IBD.

\section{Materials and methods}

Materials. A total of 40 female BALB/C mice aged 8 weeks and weighing $25 \mathrm{~g}$ (from the SPF grade Laboratory Animal Center of Harbin Medical University Public Health College) were used in this study. The study was carried out in strict accordance with the recommendations in the Guide for the Care and Use of Laboratory Animals of the National Institutes of Health. The animal use protocol was reviewed and approved by the Institutional Animal Care and Use Committee (IACUC) of Shengjing Hospital of China Medical University.

Establishment of experimental model. After weighing and assigning an ID, the BALB/C mice were randomly divided into the normal control and IBD model groups comprising 5 and 35 mice, respectively. The normal control group was normally fed. With reference to the literature, an IBD mice model was established by enema using a solution of TNBS (Sigma, St. Louis, MO, USA). Specifically, the mice were fasted for $24 \mathrm{~h}$ prior to TNBS enema and anesthetized by an 
intraperitoneal injection of $0.08 \mathrm{ml} \mathrm{5 \%}$ chloral hydrate. TNBS and $50 \%$ ethanol solution were mixed at a 1:1 ratio and a total of $0.2 \mathrm{ml}$ of the mixture was used for the enema. The mice received a normal diet following the procedure. The model group mice were sacrificed on days 1, 2, 3, 5, 7, 14 and 21 following the TNBS enema and the normal control mice were sacrificed on day 3. Colon tissues with evident damage were removed by dissection and preserved at $-80^{\circ} \mathrm{C}$ for ELISA analysis. On day 3, peripheral blood, spleen and mesenteric lymph nodes from the normal and IBD mice were also obtained when sacrificing the mice.

Peripheral blood mononuclear cells (PBMCs). Blood was drawn from the eyeballs of the mice, placed in anticoagulant tubes and centrifuged in Ficoll-Hypaque density gradient separation solution to obtain PBMCs.

Spleen mononuclear cells (SMCs). Suspensions of mouse spleen cells were centrifuged in Ficoll-Hypaque density gradient separation solution to isolate the SMCs.

Culturing of SMCs. SMCs isolated from the mice 3 days after TNBS enema were divided into 3 groups, each containing $1 \times 10^{6} / \mathrm{ml}$ cells. The cells were placed into RPMI-1640 culture medium and $1 \mu \mathrm{g} / \mathrm{ml}$ anti-IL-17 antibody, $10 \mu \mathrm{g} / \mathrm{ml}$ anti-IL-17 antibody or an equal amount of PBS were added. The same number of SMCs from the normal control group were also placed in RPMI-1640 culture medium and an equal amount of PBS was added. Cells from all 4 groups were cultured at $37^{\circ} \mathrm{C}$ in a $5 \% \mathrm{CO}_{2}$ incubator and removed after $24 \mathrm{~h}$.

ELISA. Tissues were homogenized and centrifuged in order to generate a supernatant. An ELISA procedure was performed following the instructions provided with the kit (JingMei Biotechnology Co., Ltd., Shenzhen, China) and the absorbance value of each well was read at $450 \mathrm{~nm}$ after terminating the reaction. A standard curve was plotted with OD values as the $y$-axis and standard concentrations as the abscissa. Sample concentrations were calculated according to the corresponding OD value.

Western blot analysis. Western blot analysis was used to detect IL-17 protein expression in the PBMCs, SMCs, mesenteric lymph node cells and colon tissues of the normal control mice and disease model mice sacrificed on day 3. First, total protein was extracted from the cells and tissues of each group and UV spectrophotometry was used for protein quantification. Protein samples were then subjected to SDS-PAGE and transferred onto PVDF membranes following electrophoresis. The membranes were blocked at room temperature for $2 \mathrm{~h}$ and incubated with 1:800 rabbit anti-mouse anti-IL-17 primary antibody at $4^{\circ} \mathrm{C}$ overnight. After washing with PBS, the membranes were incubated with 1:1,000 goat anti-rabbit IgG/ HRP secondary antibody at room temperature for $2 \mathrm{~h}$, washed 3 times, reacted with chemiluminescence reagents for $5 \mathrm{~min}$, exposed and then developed.

RT-PCR. Total cellular RNA was extracted following the kit instructions (Microgene Co., Shanghai, China) and UV spectrophotometry was used to determine the RNA quality and concentration in the samples. RNA was synthesized into cDNA by a reverse transcription reaction for later PCR amplification. The primers used for the internal control $\beta$-actin were: forward, GAATACTCTATTGCCGATGGT and reverse, CGATGGGTTTGCGTTTG; amplification length, 722 bp. The primers for tumor necrosis factor (TNF)- $\alpha$ were: forward, TTACGCCTTTGAAGTTAGCAG and reverse, CGTCC AAATACATCGCAAC; amplification length, 498 bp. For IL-6, the primers were: forward, ACAACGGGTGGAAC ATTACC and reverse, TGGGTTTGCGTTTGTGAG; amplification length, $422 \mathrm{bp}$. For interferon- $\gamma($ IFN- $\gamma)$, the primers were: forward, ACCCTCCTGGTTATTGAGCC and reverse, TGGTAATGTTCCACCCGTTG; amplification length, 288 bp. The synthesized primers were purchased from Shanghai Biotechnology Co., Ltd. (Shanghai, China). The PCR products were subjected to electrophoresis on a $1.5 \%$ agarose gel and analyzed using a UV gel imaging analysis system. The relative expression levels of the target genes were calculated as the ratio of the absorbance of the target gene band to that of the internal control.

Statistical analysis. Experimental data were analyzed by ANOVA using SPSS 13.0 software and $p<0.05$ was considered to indicate a statistically significant result.

\section{Results}

ELISA. Following the administration of TNBS by enema, ELISA was used to detect the expression levels of IL-17 and IFN- $\gamma$ in the mouse colon tissues. The results revealed that the levels of IL-17 were significantly increased ( $\mathrm{p}<0.05$ compared with the normal control group) on day 1 following the TNBS treatment, peaked on day 3 and decreased afterwards. The IL-17 levels in the model group remained significantly different from those in the normal control group until day $7(\mathrm{p}<0.05)$, but decreased to levels of no significant difference from the control on days 14 and 21 ( $>>0.05)$. The levels of IFN- $\gamma$ had not significantly increased on day 1 ( $p>0.05$ compared with the normal control group) and slowly increased afterwards to a significant level on day $3(\mathrm{p}<0.05)$. The IFN- $\gamma$ level peaked on day 7 and subsequently began to decrease. On days 14 and 21, the IFN- $\gamma$ levels were significantly different from those in the control group $(\mathrm{p}<0.05)$ (Table I). These results suggest that the involvement of IL-17 in the TNBS-induced colitis occurred earlier than that of IFN- $\gamma$, while the effect of IFN- $\gamma$ in the target tissue was sustained for longer since its expression remained detectable even after the elevated expression of IL-17 had disappeared. Since the expression of IL-17 reached its highest levels on day 3 , the model mice on day 3 after TNBS treatment were selected for further study.

Western blot analysis. As shown in Fig. 1, western blot analysis was used to detect IL-17 protein expression in the PBMCs, SMCs, mesenteric lymph node cells and colon tissues of the normal control group and model group 3 days after TNBS treatment. The results revealed that the IL-17 levels in the SMCs, mesenteric lymph node cells and colon tissues of the model group were significantly higher than those of the normal control group $(\mathrm{p}<0.01)$ and were particularly high in colon tissues. The IL-17 levels in the PBMCs of the model group were not 


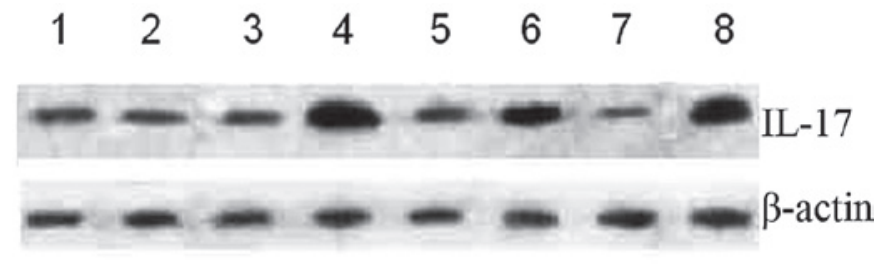

Figure 1. IL-17 protein expression in various tissues detected by western blot analysis. Lane 1, control peripheral blood mononuclear cells (PBMCs); lane 2, model group PBMCs; lane 3, control mesenteric lymph nodes; lane 4, model group mesenteric lymph nodes; lane 5, control SMCs; lane 6, model group spleen mononuclear cells (SMCs); lane 7, control intestinal tissues; lane 8, model group intestinal tissues.

Table I. ELISA results of IL-17 and IFN- $\gamma$ levels in mouse colon tissues.

\begin{tabular}{lcr}
\hline Group & IL-17 $(\mathrm{pg} / \mathrm{ml})$ & IFN- $\gamma(\mathrm{pg} / \mathrm{ml})$ \\
\hline Day 0 & $89.4 \pm 23.7$ & $54.6 \pm 16.5$ \\
Day 1 & $118.7 \pm 29.7^{\mathrm{a}}$ & $60.8 \pm 18.9$ \\
Day 2 & $160.1 \pm 34.7^{\mathrm{a}}$ & $67.4 \pm 20.1$ \\
Day 3 & $219.4 \pm 57.8^{\mathrm{a}}$ & $78.6 \pm 19.8^{\mathrm{a}}$ \\
Day 5 & $187.5 \pm 44.6^{\mathrm{a}}$ & $90.6 \pm 30.4^{\mathrm{a}}$ \\
Day 7 & $159.8 \pm 36.8^{\mathrm{a}}$ & $109.8 \pm 29.8^{\mathrm{a}}$ \\
Day 14 & $98.4 \pm 18.7$ & $90.6 \pm 20.1^{\mathrm{a}}$ \\
Day 21 & $90.8 \pm 24.6$ & $77.8 \pm 26.3^{\mathrm{a}}$ \\
\hline
\end{tabular}

Day 0, normal control group. In the day 1,2, 3, 5, 7, 14 and 21 groups, mice were sacrificed on days $1,2,3,5,7,14$ or 21 , respectively, after the administration of 2,4,6-trinitrobenzenesulfonic acid (TNBS) by enema. All other groups were compared with the normal control group, ${ }^{\mathrm{a}} \mathrm{p}<0.05$.

significantly different from those of the control group ( $\mathrm{p}>0.05)$ (Table II).

$R T$-PCR. As shown in Fig. 2, SMCs from the day 3 model group mice were treated with PBS, $1 \mu \mathrm{g} / \mathrm{ml}$ anti-IL-17 antibody or $10 \mu \mathrm{g} / \mathrm{ml}$ anti-IL-17 antibody, respectively, and the SMCs from the normal control group mice were treated with PBS only. The cells were cultured for $24 \mathrm{~h}$ and RT-PCR was used to detect the expression of TNF- $\alpha$, IFN- $\gamma$ and IL- 6 mRNA. The TNF- $\alpha$, IFN- $\gamma$ and IL- 6 levels of the PBS model group were significantly different from those of the normal PBS control group $(\mathrm{p}<0.05)$. The TNF- $\alpha$ and IL-6 levels in the $1 \mu \mathrm{g} / \mathrm{ml}$ antibody-treated model group were decreased compared with those of the PBS model group but the differences were not statistically significant $(\mathrm{p}>0.05)$; the IFN- $\gamma$ levels in the $1 \mu \mathrm{g} / \mathrm{ml}$ antibody-treated model group were also not significantly different from those in the PBS model group ( $\mathrm{p}>0.05)$. The TNF- $\alpha$ and IL-6 levels in the $10 \mu \mathrm{g} / \mathrm{ml}$ antibody-treated model group were significantly different from those in the PBS model group $(\mathrm{p}<0.05)$, while the difference in IFN- $\gamma$ levels between the $10 \mu \mathrm{g} / \mathrm{ml}$ antibody-treated model group and the PBS model group was not statistically significant $(\mathrm{p}>0.05)$ (Table III). The results indicate that the expression levels of TNF- $\alpha$, IFN- $\gamma$ and IL- 6 mRNA increased in the SMCs of the
Table II. Western blot analysis detection of IL-17 protein levels in various tissues.

\begin{tabular}{lcccc}
\hline Group & PBMCs & $\begin{array}{c}\text { Mesenteric } \\
\text { lymph nodes }\end{array}$ & SMCs & $\begin{array}{c}\text { Colon } \\
\text { tissues }\end{array}$ \\
\hline Model & $0.83 \pm 0.15$ & $3.98 \pm 0.54^{\mathrm{a}}$ & $3.01 \pm 0.52^{\mathrm{a}}$ & $2.06 \pm 0.30^{\mathrm{a}}$ \\
Control & $1.03 \pm 0.18$ & $0.82 \pm 0.13$ & $1.02 \pm 0.19$ & $0.28 \pm 0.06$ \\
\hline
\end{tabular}

PBMCs, peripheral blood mononuclear cells, SMCs, spleen mononuclear cells. ${ }^{\mathrm{a}} \mathrm{p}<0.01$ compared with the normal control group.

Table III. Comparison of TNF- $\alpha$, IFN- $\gamma$ and IL-6 mRNA levels.

\begin{tabular}{lccc}
\hline Group & TNF- $\alpha$ & IFN- $\gamma$ & IL-6 \\
\hline PBS model & $0.54 \pm 0.11^{\mathrm{a}}$ & $0.53 \pm 0.10^{\mathrm{a}}$ & $0.92 \pm 0.18^{\mathrm{a}}$ \\
$1 \mu \mathrm{g}$ model & $0.49 \pm 0.12^{\mathrm{b}}$ & $0.52 \pm 0.13^{\mathrm{b}}$ & $0.84 \pm 0.20^{\mathrm{b}}$ \\
$10 \mu \mathrm{g}$ model & $0.29 \pm 0.06^{\mathrm{c}}$ & $0.50 \pm 0.12$ & $0.77 \pm 0.15^{\mathrm{c}}$ \\
PBS control & $0.28 \pm 0.07$ & $0.40 \pm 0.08$ & $0.73 \pm 0.13$
\end{tabular}

${ }^{\mathrm{a}} \mathrm{p}<0.05$ compared with the PBS control group; ${ }^{\mathrm{b}} \mathrm{p}>0.05$ compared with the PBS model group; ${ }^{c} \mathrm{p}<0.05$ compared with the PBS model group.

TNBS-induced colitic mice and that the application of an antiIL-17 antibody reduced the secretion of TNF- $\alpha$ and IL-6, but had no effect on IFN- $\gamma$ secretion.

\section{Discussion}

It is currently considered that the pathogenesis of IBD is related to a series of susceptibility genes, environmental factors and immune system abnormalities (6). A number of factors of the intestinal mucosal immune system, including cytokines and immune regulation, are involved in the pathogenesis of IBD.

The role of $\mathrm{CD}^{+} \mathrm{T}$ cells in the pathogenesis of IBD has been well-recognized. Previous studies have suggested that the IL-12/IFN- $\gamma$ axis-mediated Th1-type immune response is closely related to the incidence of IBS; however, TNBS is able to induce colitis in mice even following IFN- $\gamma$ knockout or anti-IFN- $\gamma$ monoclonal antibody application (7), indicating that IFN- $\gamma$ is not the key factor in colitis induced by TNBS. Th17 cells have been confirmed to be a CD4 ${ }^{+}$T-cell subtype. Previous studies have shown that IL-23 is capable of stimulating memory $\mathrm{CD}^{+} \mathrm{T}$ cells to produce IL-17 and is involved in the proliferation of Thl7/ThlL-17 cells and the maintenance of their survival (8). Related studies using mice revealed that almost no Th17 cells were formed in the absence of IL-23 $(9,10)$. It has been demonstrated that IL-17 expression is significantly increased in patients with a variety of autoimmune diseases and animal models of these diseases, and its functional status is closely related to the onset of numerous autoimmune diseases (11). A previous study found that the IL-23/Thl7 cell axis is closely related to the pathogenesis of IBD (12). Blaschitz and Raffatellu (13) revealed that IL-17 was not expressed in normal colonic mucosa, ischemic colitis or infectious colitis. However, IL-17 expression was significantly increased in the affected mucosa of active IBD 


\section{$\begin{array}{llllllllllllllllll}1 & 2 & 3 & 4 & 5 & 6 & 7 & 8 & 9 & 10 & 11 & 12 & 13 & 14 & 15 & 16 & 17\end{array}$}

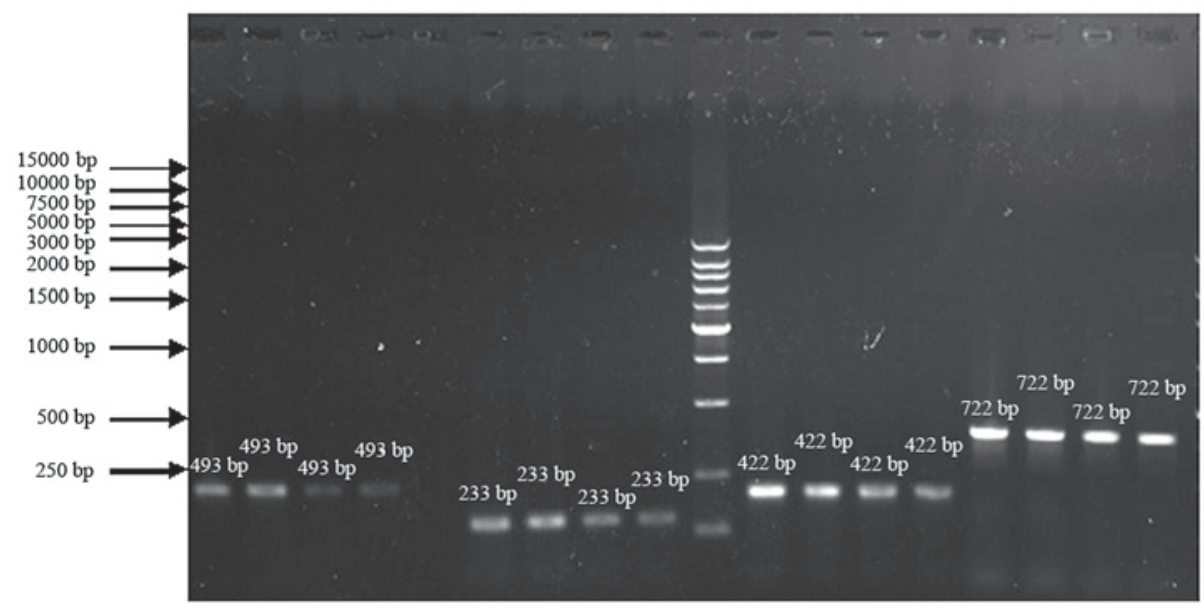

Figure 2. mRNA expression of TNF- $\alpha$, IFN- $\gamma$ and IL-6 detected by RT-PCR. Lanes 1-4: TNF- $\alpha$ mRNA for the PBS model, $1 \mu \mathrm{g}$ model, $10 \mu \mathrm{g}$ model and PBS normal control groups, respectively. Lanes 5-8: IFN- $\gamma$ mRNA for the PBS model, $1 \mu \mathrm{g}$ model, $10 \mu \mathrm{g}$ model and PBS normal control groups, respectively. Lane 9: Marker. Lanes 10-13: IL-6 mRNA for the PBS model, $1 \mu \mathrm{g}$ model, $10 \mu \mathrm{g}$ model and PBS normal control groups, respectively. Lanes $14-17$ : $\beta$-actin mRNA for the PBS model, $1 \mu \mathrm{g}$ model, $10 \mu \mathrm{g}$ model and PBS normal control groups, respectively.

patients. IL-17R knockout or overexpression of IL-17R IgGl fusion protein has been reported to significantly inhibit TNBS-induced colitis (14), indicating that Th17 cells are significantly involved in the pathogenesis of IBD. However, further studies focusing on Th17 cells revealed that Th17 cells are not the only effector cells to induce organ-specific autoimmune diseases. A previous study demonstrated that rats with a defective p19 subunit of IL-23 were highly susceptible to hapten-induced colitis, which may be related to the overproduction of IL-12 by intestinal dendritic cells in an IL-23 deficient environment (15). Thus, it is likely that Th1 cells and Th17 cells synergize to induce organ-specific autoimmune diseases. Therefore, the mechanisms by which Th17 and Th1 cells contribute to the pathogenesis of autoimmune diseases require urgent investigation.

In the current study, TNBS was administered to establish an IBD model and western blot analysis were used to detect IL-17 expression in affected colon tissues, mesenteric lymph node cells, SMCs and PBMCs. Compared with the normal control group, the results revealed that IL-17 expression was significantly increased in the affected local area, which is consistent with previous reports (14). However, the IL-17 expression levels in PBMCs did not increase, suggesting that Th17 cells mainly act locally rather than systemically, which further indicates that the immune response mediated by memory $\mathrm{T}$ lymphocytes is tissue- and organ-specific (16). Since IL-17 is mainly produced by memory T lymphocytes, its elevation locally may induce an inflammatory response at a certain location and specific to this location (17).

An ELISA method was used in this study to detect the expression of the Th17 cytokine IL-17 and the Th1 cytokine IFN- $\gamma$ in mice. A specific anti-IL-17 monoclonal antibody was also applied to block IL-17 and the effect on IFN- $\gamma$ expression was evaluated. The results revealed that the levels of IL-17 peaked prior to those of IFN- $\gamma$ while IFN- $\gamma$ was sustained for longer in the target tissues, even after the elevated expression levels of IL-17 had disappeared. This is consistent with the results of Batten et al (18) in a study which tested the dynamic expression of cytokines in the cerebrospinal fluid of an experimental autoimmune encephalomyelitis (EAE) model. Our study confirmed that Th17 and Th1 cells played important roles at different stages of IBD, i.e., the effect of the Th17 cells was produced sooner than that of the Th1 cells to initiate acute inflammation, while the Th1 cells were involved in sustaining inflammation subsequently. This suggests that the Th17 and Th1 cells are involved in the pathogenesis of IBD. In addition, an anti-IL-17 antibody was not able to block IFN- $\gamma$ secretion, further suggesting that the Th17 and Th1 cells have a synergistic effect in the pathogenesis of IBD (19).

Furthermore, pro-inflammatory cytokines play an indispensable role in the pathogenesis of IBD (20). Among a large number of pro-inflammatory cytokines, IL- 6 and TNF- $\alpha$ are frequently used for studying the pathogenesis of IBD $(21,22)$, as the expression levels of both are significantly increased in the local mucosa of IBD patients. The application of anti-TNF- $\alpha$ antibody has been revealed to significantly improve certain pathological changes in the IBD mice model and reduce mortality, as well as ameliorate the clinical symptoms of IBD patients $(23,24)$. In the current study, semi-quantitative RT-PCR confirmed that the levels of TNF- $\alpha$ and IL-6 were increased in the SMCs of colitic mice. In order to verify the relationship between Th17 cells and these two cytokines, we added anti-IL-17 antibody to the cell culture medium and found that the expression levels of IL-6 and TNF- $\alpha$ decreased in direct proportion to the concentration of antibody added. This result suggests that Th17 cells further induce the onset of IBD by stimulating the production of the downstream products TNF- $\alpha$ and IL-6.

The current study demonstrates that $\mathrm{Th} 17$ cells play a key role in the early stage of IBD onset and that this effect is tissue- and organ-specific, as well as direct-targeting. In addition, Thl7 cells execute an inflammation-sustaining function since blocking the secretion of cytokines by Th17 reduces the generation of IL- 6 and TNF- $\alpha$, indicating that the downstream effects of IL-17/ IL-17R pathway activation are important in the pathogenesis of IBD. Therefore, further study on the mechanisms of Th17 cells may help in the search for an effective treatment for IBD. 


\section{References}

1. Ouyang Q, Tandon R, Goh KL, Ooi CJ, Ogata H and Fiocchi C: The emergence of inflammatory bowel disease in the Asian Pacific region. Curr Opin Gastroenterol 21: 408-413, 2005.

2. Jiang Y, Xia B, Jiang L, et al: Association of CTLA-4 gene microsatellite polymorphism with ulcerative colitis in Chinese patients. Inflamm Bowel Dis 12: 369-373, 2006.

3. Vermeire S: Genetic susceptibility and application of genetic testing in clinical management of inflammatory bowel disease. Aliment Pharmacol Ther 24 (Suppl 3): 2-10, 2006.

4. Weaver CT, Harrington LE, Mangan PR, Gavrieli M and Murphy KM: Th17: an effector CD4 T cell lineage with regulatory T cell ties. Immunity 24: 677-688, 2006.

5. Harrington LE, Mangan PR and Weaver CT: Expanding the effector CD4 T-cell repertoire: the Th17 lineage. Curr Opin Immunol 18: 349-356, 2006.

6. Podolsky DK: Inflammatory bowel disease. N Eng J Med 347: 417-429, 2002

7. Iwakura $\mathrm{Y}$ and Ishigame H: The IL-23/IL-17 axis in inflammation. J Clin Invest 116: 1218-1222, 2006.

8. Park H, Li Z, Yang XO, et al: A distinct lineage of CD4 T cells regulates tissue inflammation by producing interleukin 17 . Nat Immunol 6: 1133-1141, 2005.

9. Veldhoen M, Hocking RJ, Atkins CJ, Locksley RM and Stockinger B: TGFbeta in the context of an inflammatory cy tokine milieu supports de novo differentiation of IL-17-producing T cells. Immunity 24: 179-189, 2006.

10. Langrish CL, Chen Y, Blumenschein WM, et al: IL-23 drives a pathogenic $\mathrm{T}$ cell population that induces autoimmune inflammation. J Exp Med 201: 233-240, 2005.

11. Yamada H: Th17 cells and human arthritic diseases. Nihon Rinsho Meneki Gakkai Kaishi 33: 214-221, 2010 (In Japanese).

12. Hue S, Ahern P, Buonocore S, et al: Interleukin-23 drives innate and T cell- tmediated intestinal inflammation. J Exp Med 203: 2473-2483, 2006.

13. Blaschitz C and Raffatellu M: Th17 cytokines and the gut mucosal barrier. J Clin Immunol 30: 196-203, 2010.
14. Zhang Z, Zheng M, Bindas J, Schwarzenberger P and Kolls JK: Critical role of IL-17 receptor signaling in acute TNBS-induced colitis. Inflamm Bowel Dis 12: 382-388, 2006.

15. Becker C, Dornhoff H, Neufertet C, et al: Cutting edge: IL-23 Eross-rugulates IL-12 production in T cell-dependent experimental colitis. J Immunol 177: 2760-2764, 2006.

16. Davidson NJ, Leach MW, Fort MM, et al: T helper cell 1-type $\mathrm{CD}^{+} \mathrm{T}$ cells, but not $\mathrm{B}$ cells, mediate colitis in interleukin 10-deficient mice. J Exp Med 184: 241-225, 1996.

17. Fossiez F, Banchereau J, Murray R, Van Kooten C, Garrone P and Lebecque S: Interleukin-17. Int Rev Immunol 16: 541-551, 1998.

18. Batten M, Li J, Yi S, et al: Interleukin-27 limits autoimmune encephalomyelitis by suppressing the development of interleukin 17-producing T cells. Nat Immunol 7: 929-936, 2006.

19. Elson CO, Cong Y, Weaver CT, et al: Monoclonal anti-interleukin 23 reverses active colitis in a T cell-mediated model in mice. Gastroenterology 132: 2359-2370, 2007.

20. Targan SR and Karp LC: Defects in mucosal immunity leading to ulcerative colitis. Immunol Rev 206: 296-305, 2005.

21. Reddy KP, Markowitz JE, Ruchelli ED, Baldassano RN and Brown KA: Lamina propria and circulating interleukin-8 in newly and previously diagnosed pediatric inflammatory bowel disease patients. Dig Dis Sci 52: 365-372, 2007.

22. Hong DS, Angelo LS and Kurzrock R: Interleukin-6 and its receptor in cancer: implications for translational therapeutics. Cancer 110: 1911-1928, 2007.

23. Van Assche G, Magdelaine-Beuzelin C, D'Haens G, et al: Withdrawal of immunosuppression in Crohns disease treated with seheduled infliximab maintaince: a randomized trial. Gastroenterology 134: 1861-1868, 2008.

24. Orlando A, Mocciaro F, Civitavecchia G, Scimeca D and Cottone M: Minimizing infliximab toxicity in the treatment of inflammatory bowel disease. Dig Liver Dis 40 (Suppl 2): S236-S246, 2008. 